\title{
INTEGRATED VELOCITY AND DISPLACEMENT OF STRONG EARTHQUAKE GROUND MOTION
}

\author{
By G. V. Berg and G. W. Housner
}

\begin{abstract}
The earthquake ground accelerations recorded at El Centro, 30 December 1934; El Centro, 18 May 1940; Olympia, Washington, 13 April 1949; and Taft, California, 21 July 1952, have been integrated with a digital computer to obtain at each location the three components of ground velocity and ground displacement. Maximum horizontal displacements of 10 and 20 inches are indicated, and maximum vertical displacements of 5 inches are indicated.
\end{abstract}

Strong ground motions are usually recorded by accelerometers since the ground acceleration is the quantity most pertinent to engineering studies; however, for some engineering purposes a knowledge of ground displacements during strong earthquakes is important. In addition to accelerometers (period $0.06 \mathrm{sec}$ ) the United States Coast and Geodetic Survey maintains a number of Carder displacement meters (period $2.5 \mathrm{sec}$ ) and a few displacement meters having a natural period of 10 seconds. The natural period of the Carder displacement meter is much too short to give an accurate measure of the ground displacement during strong ground motion, ${ }^{1}$ and even the 10 -second period instrument probably does not give accurate measurements of strong ground motion. The difficulties involved in installing and maintaining a network of displacement meters having periods sufficiently long to record accurately strong ground motions are truly formidable. The late Harry Wood, of the Seismological Laboratory at the California Institute of Technology, designed and had constructed a pair of horizontal pendulums that presumably would have accomplished satisfactory measurements but their size and weight precluded their installation in the basements of ordinary commercial buildings where the accelerometers are installed.

Although ground velocities and displacements are not of as much interest to engineers as ground accelerations there is still interest in knowing the magnitudes involved and, therefore, in the past there have been attempts at integrating the accelerations to obtain these quantities. ${ }^{2,3}$ When done graphically or numerically the satisfactory integration of the accelerograms is very difficult. The chief difficulty arises from the fact that the true axis (zero acceleration) of the accelerogram is not known and hence it must be approximately located by trial and error. Recently when the three components of ground acceleration for the four strongest recorded ground motions were put on punch cards, it was a relatively simple matter to do the integrations for the velocities and displacements.

The accelerograms were put on punch cards as follows. First the trace was approximated as faithfully as could reasonably be accomplished with a series of straight

\footnotetext{
Manuscript received for publication August 27, 1960, and, as revised, October 13, 1960.

1 Housner, G. W. and D. E. Hudson, "The Port Hueneme Earthquake of March 18, 1957," Bull. Seism. Soc. Am., 48:163-168 (1958).

2 Neumann, F., United States Earthquakes, 1940, (Serial No. 647), U. S. Department of Commerce, 1942.

3 Housner, G. W., "Ground Displacement Computed From Strong-Motion Accelerograms," Bull. Seism. Soc. Am., 37:299-305 (1947).
} 
line segments. A temporary straight base line was drawn on the accelerograms and the coordinates of the intersection points of successive line segments, measured from the base line using some convenient scale of measurement, were recorded on punch cards.

It was assumed that the recorded initial ground velocity and ground displacement were zero. It was further assumed that in the true time-acceleration coordinates the equation of the temporary base line would take the form $c_{0}+c_{1} t+c_{2} t^{2}$, where the constants $c_{0}, c_{1}$, and $c_{2}$ would have the values that would make the mean square computed ground velocity a minimum. The punch cards were processed by computer to introduce appropriate scale factors for time and acceleration, to find the equation of the base line meeting the above conditions, and to adjust the acceleration readings accordingly. The computer produced a deck of scaled and corrected punch cards as its output.

The integrations were performed in the following manner. Let $h$ be an interval of time such that the ground acceleration is a linear function of time in the interval $(t, t+h)$, let $a_{0}, v_{0}$, and $x_{0}$ be the values of ground acceleration, velocity, and displacement at time $t$, and let $a_{1}$ be the ground acceleration at time $t+h$. The ground velocity and displacement at time $t+h$ are then

$$
\begin{aligned}
& v_{1}=v_{0}+\frac{h}{2}\left(a_{0}+a_{1}\right) \\
& x_{1}=x_{0}+h v_{0}+\frac{h^{2}}{6}\left(2 a_{0}+a_{1}\right) .
\end{aligned}
$$

By repeated use of these formulas one can advance step by step through the solution. No truncation error occurs, and roundoff error is negligible.

All computation was performed on the IBM 704 computer at The University of Michigan Computing Center.

The question of accuracy of the computed velocities and displacements is associated with the accuracy of the accelerometer as well as the accuracy of the digitized data in representing the smooth accelerogram. Comparative measurements made with a USCGS accelerometer and an instrument of much more extended frequency range indicate that the USCGS instrument gives a quite accurate representation of earthquake ground acceleration. ${ }^{4}$ There would appear to be no reason why the integrated velocities and displacements should be grossly in error, but it is not possible to make an assessment of the accuracy of the results. The three components of acceleration were integrated to obtain the velocities and displacements shown in the accompanying diagrams for the following records:

$$
\begin{aligned}
& \text { El Centro, California, } 18 \text { May } 1940 \text { (figs. 1, 2, and 3) } \\
& \text { El Centro, California, } 30 \text { December } 1934 \text { (figs. 4, 5, and 6) } \\
& \text { Olympia, Washington, } 13 \text { April } 1949 \text { (figs. 7, 8, and 9) } \\
& \text { Taft, California, 21 July } 1952 \text { (figs. 10, 11, and 12) } \\
& \text { Pasadena, California, } 21 \text { July } 1952 \text { (fig. 13) }
\end{aligned}
$$

Specific comments on the integrated curves are as follows:

\footnotetext{
${ }^{4}$ Hudson, D. E., J. L. Alford, and G. W. Housner, "Measured Response of a Structure to an Explosive-Generated Ground Shock," Bull. Seism. Soc. Am., 44:513-527 (1954).
} 
El Centro, 18 May 1940. This shock has been given a Richter Magnitude of 7.0 (formerly 6.7). The instrument was somewhat less than 10 miles southwesterly of the trace of the fault which showed relative surface displacement over a length of approximately forty or fifty miles, with a maximum relative displacement of ap-
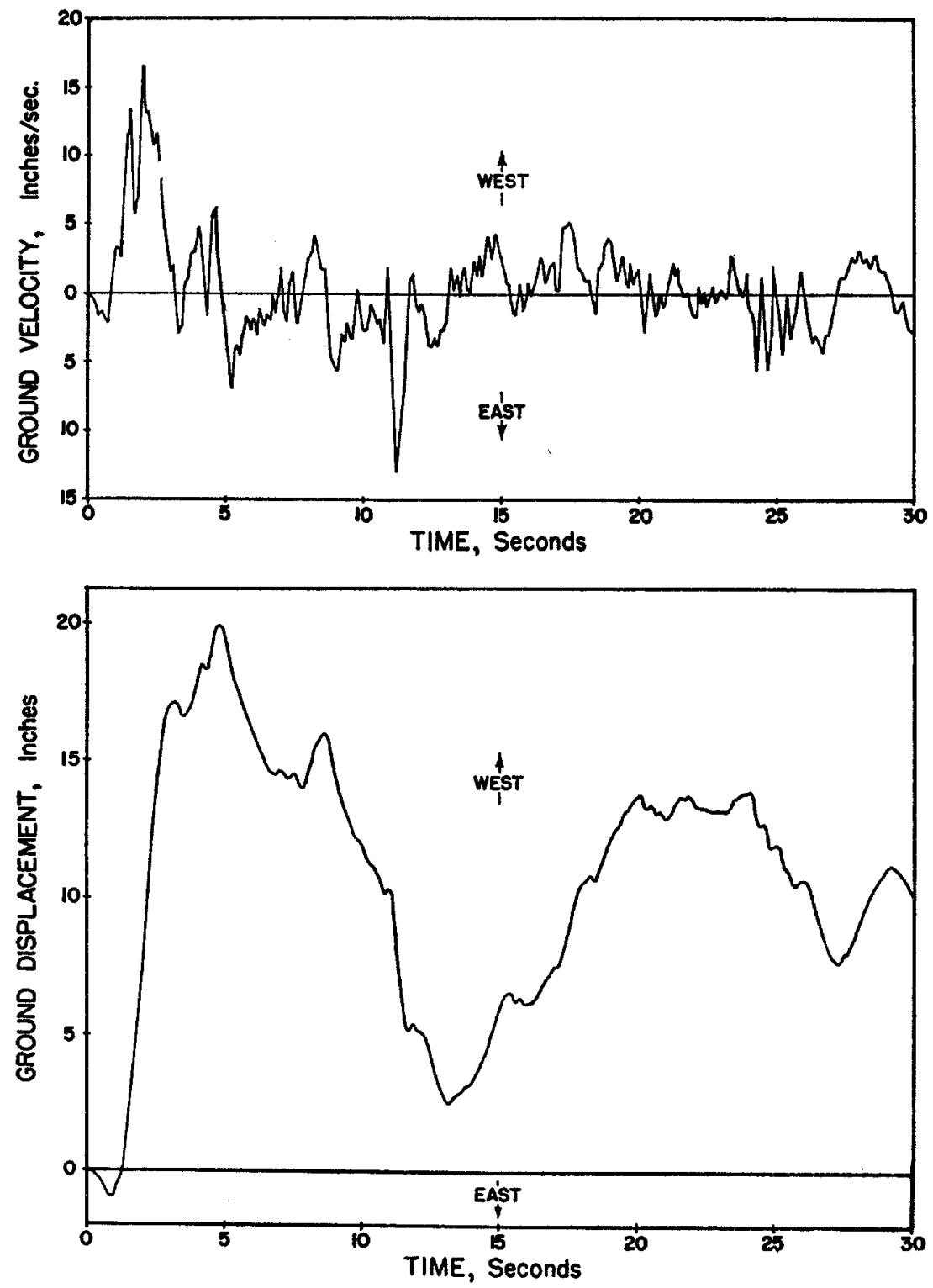

FIg. 1. El Centro, 1940, E-W component. 
proximately twelve feet. The center of the slipped length of fault was estimated to be approximately 25 to 30 miles southeasterly of the instrument. The integrated displacements indicate permanent displacements of approximately 9 inches to the west and 7 inches to the north. This is consistent in direction with the observed
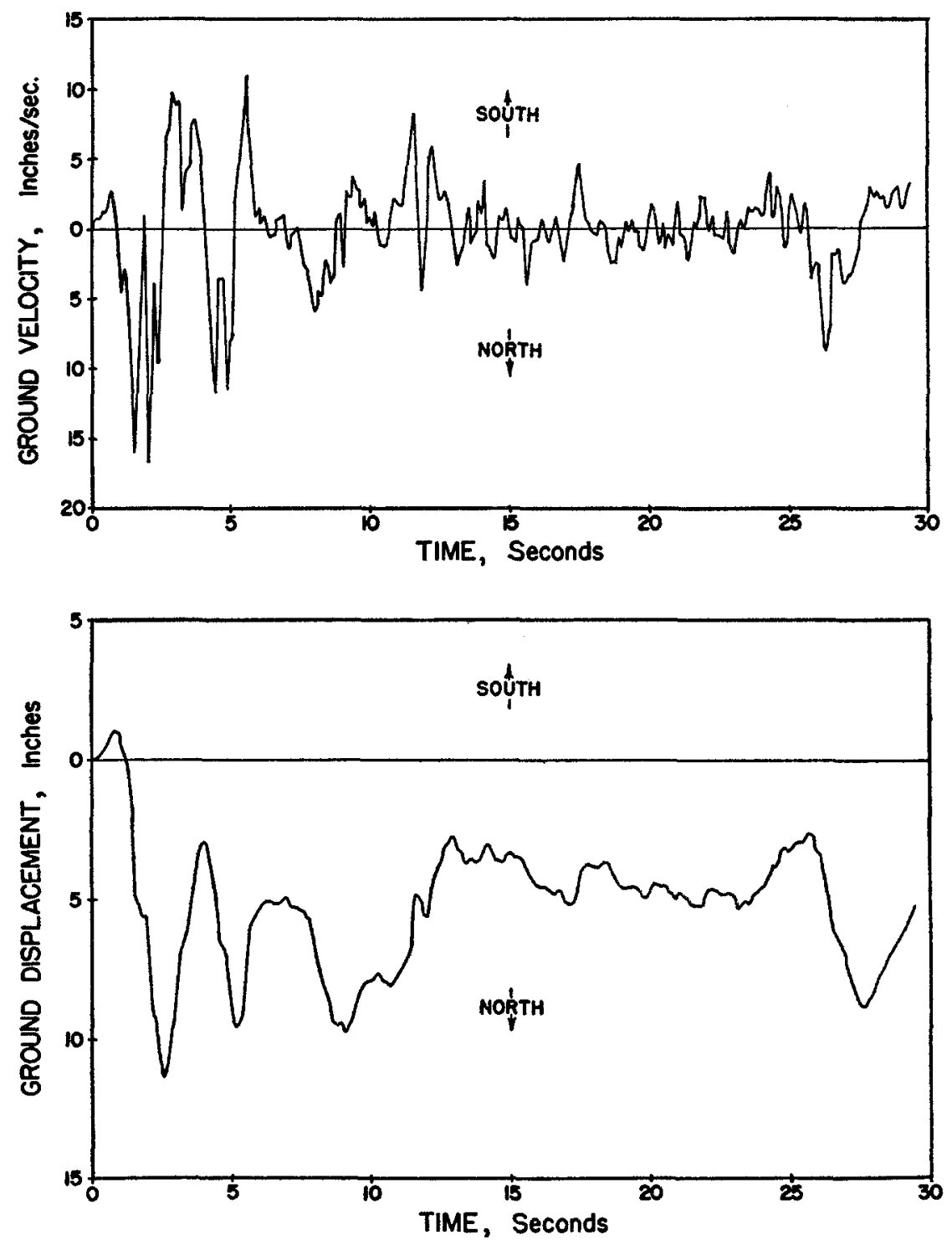

Fig. 2. El Centro, 1940, N-S component. 
fault slipping. The resultant permanent displacement of 11 to 12 inches is not unreasonable in view of the 6 feet experienced at the center of the surface trace. A permanent downward displacement of approximately 2 inches is also indicated.
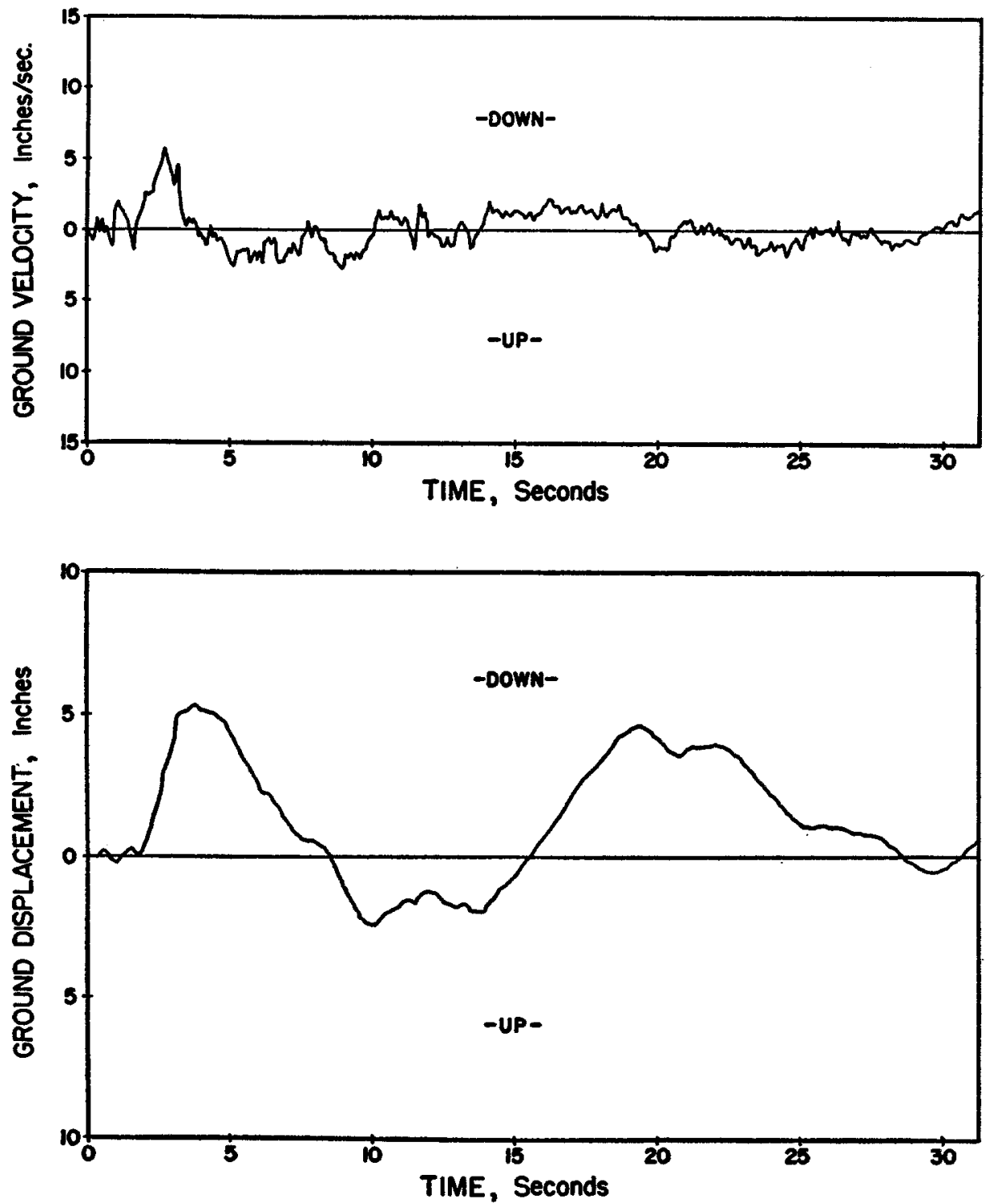

FIG. 3. El Centro, 1940, vertical component. 
El Centro, 30 December 1934. This shock of Magnitude 6.5 had a center approximately 35 miles south of the instrument. The slipping along the fault did not extend to the surface. The east-west component of the integrated motion does not indicate
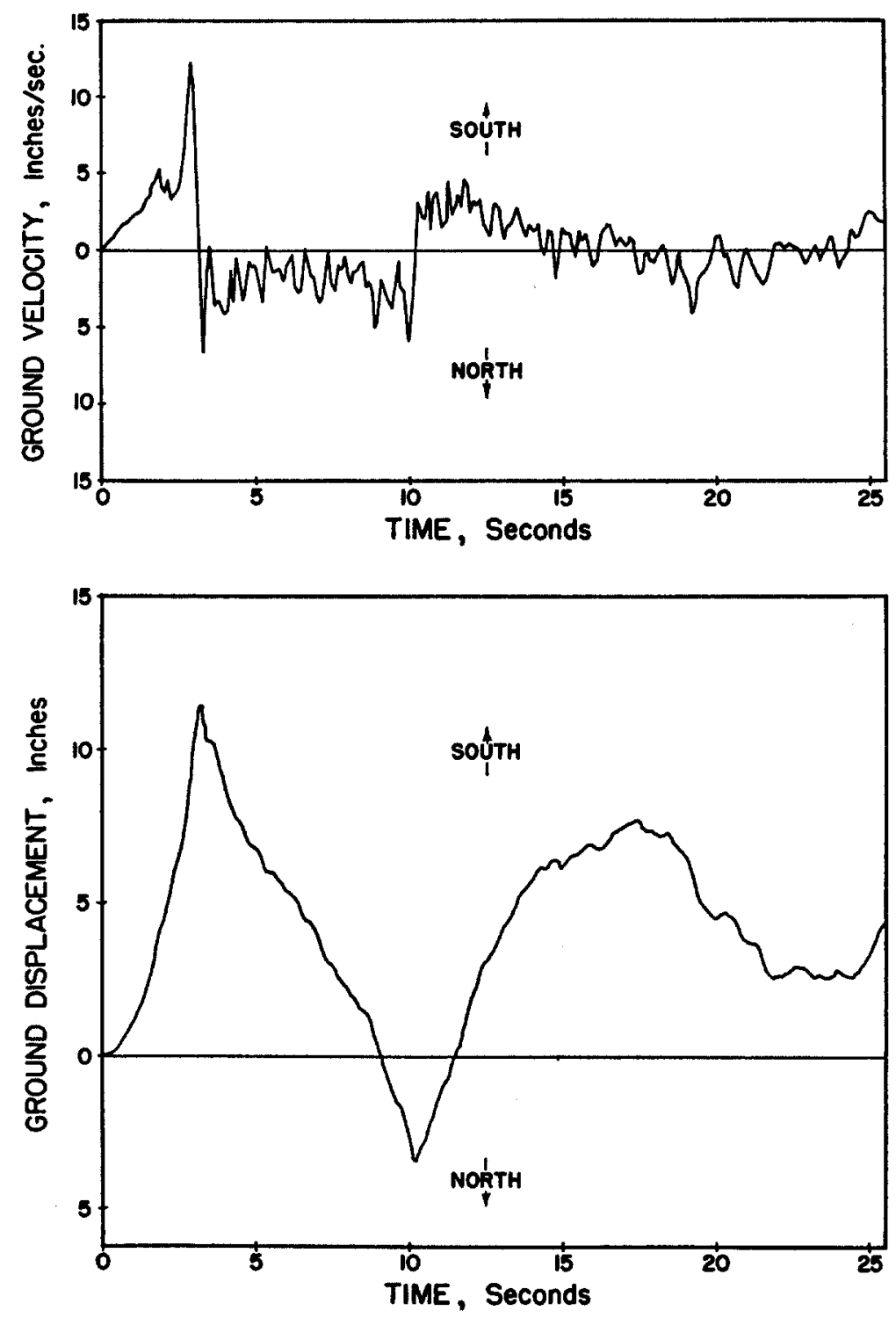

Fig. 4. El Centro, 1934, N-S component. 
any permanent displacement. The north-south component would appear to indicate a permanent displacement of 3 or 4 inches, but the step-like appearance of the velocity curve indicates that perhaps the instrument was not behaving properly.
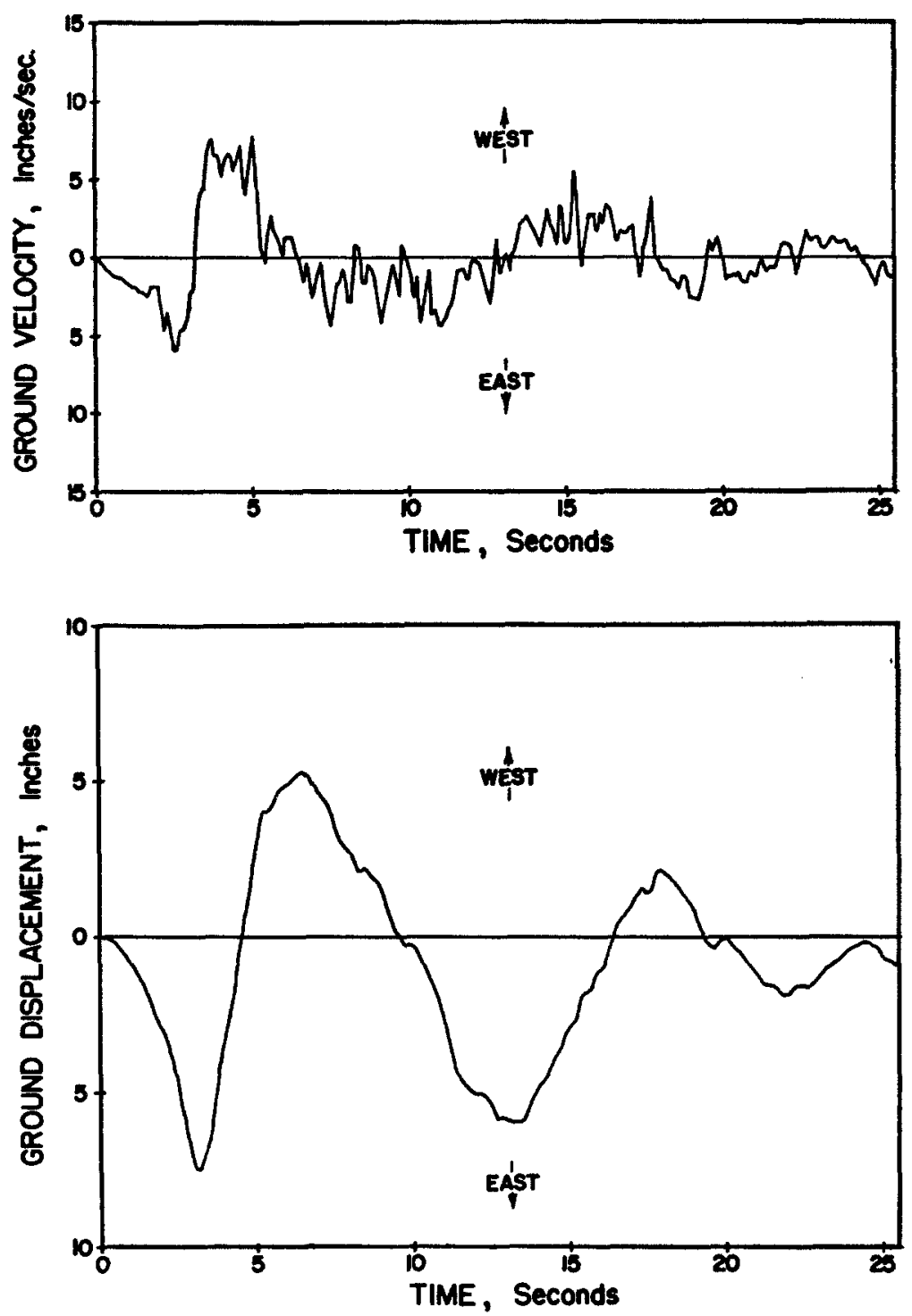

Fig. 5. El Centro, 1934, E-W component. 
In the early days of the accelerometer certain difficulties were encountered with the suspension system and shifting baselines.
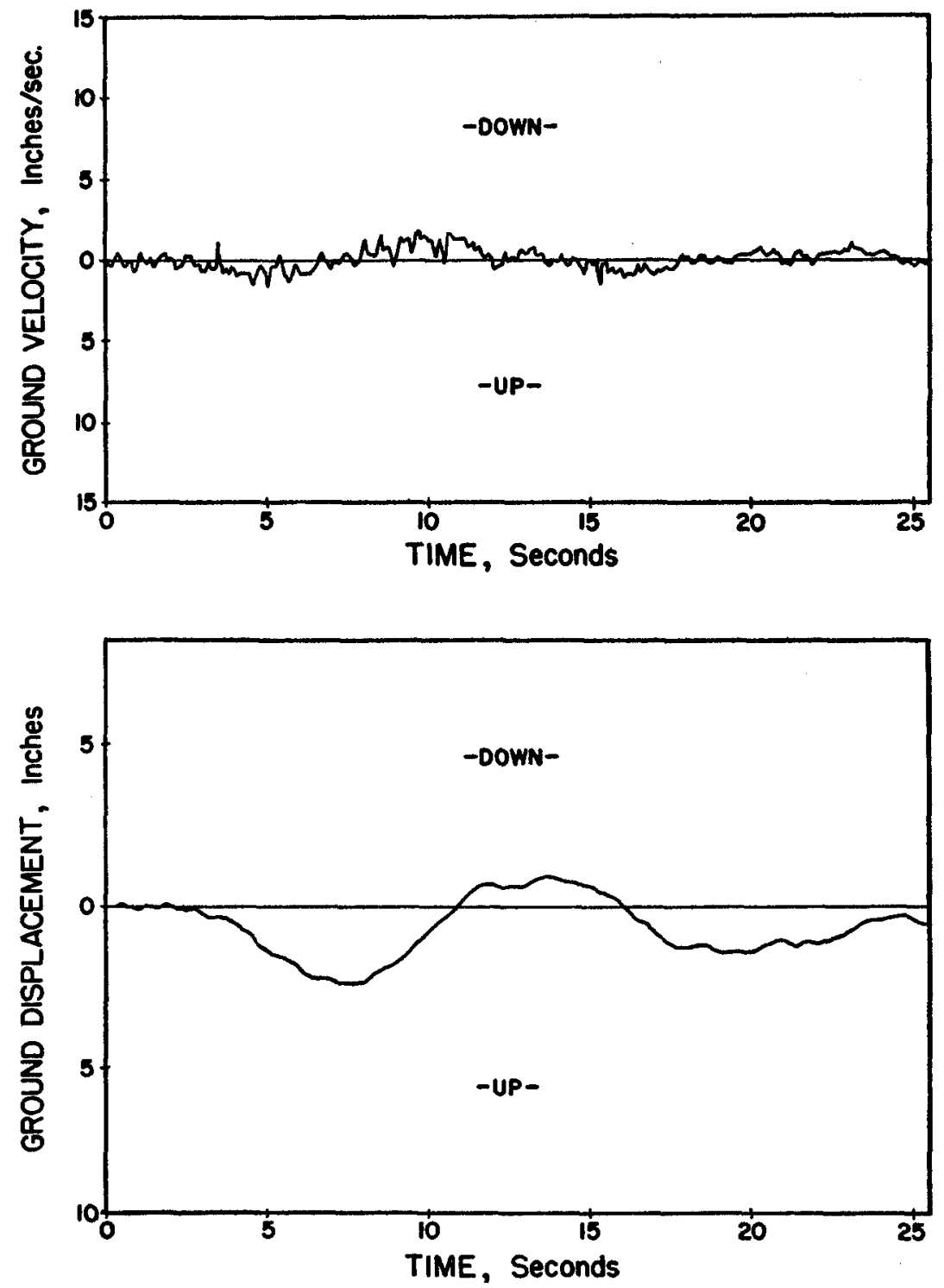

Fia. 6. El Centro, 1934, vertical component. 
Olympia, 13 April 1949. This shock of Magnitude 7.1 centered approximately 45 miles north-northeast of the instrument, and the hypocenter was located approxi-
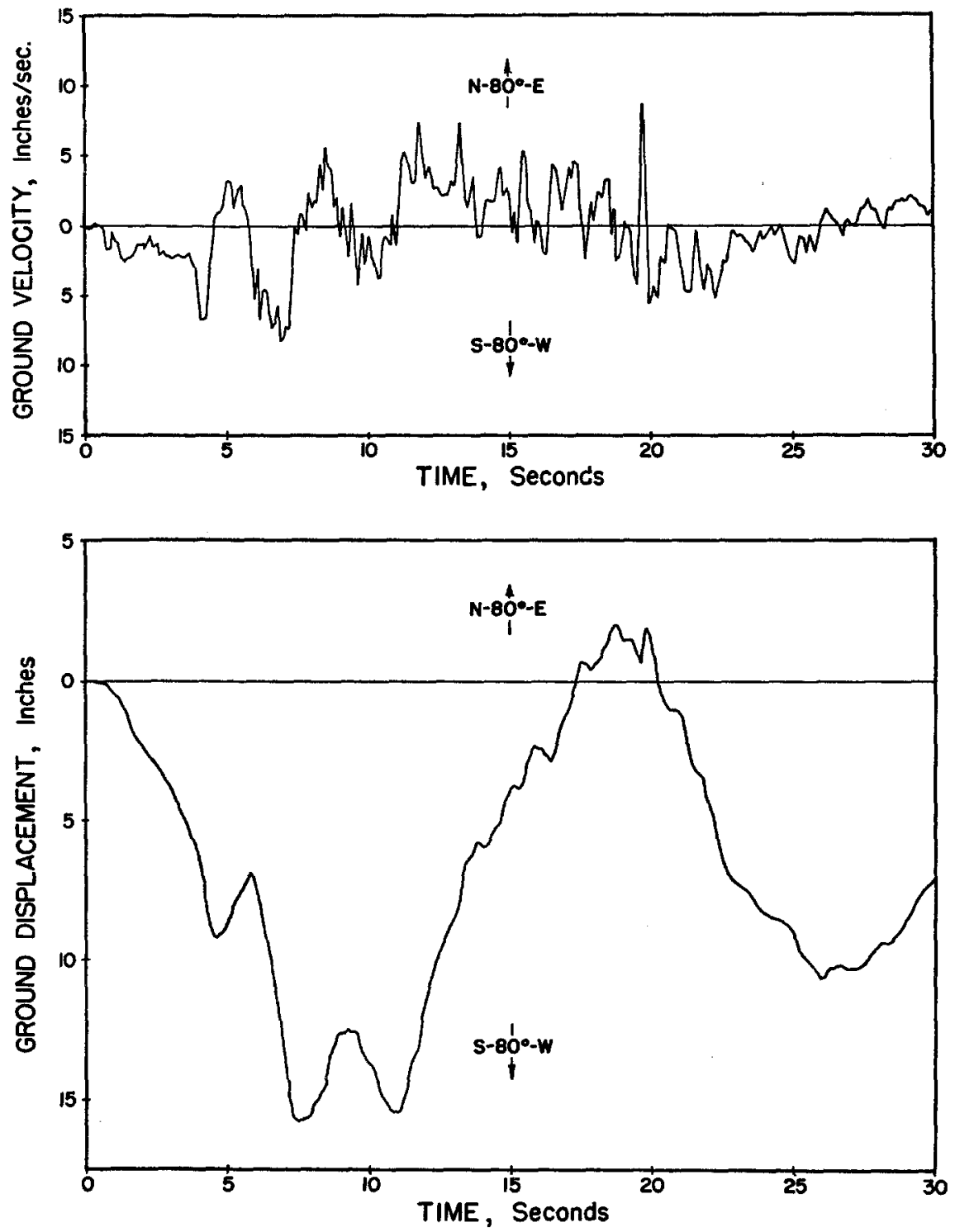

Frg. 7. Olympia, $1949, \mathrm{~N}-80^{\circ}-\mathrm{E}$ component. 
mately 45 miles beneath the surface of the ground. The north-south component of computed ground displacement indicates no permanent displacement but the other
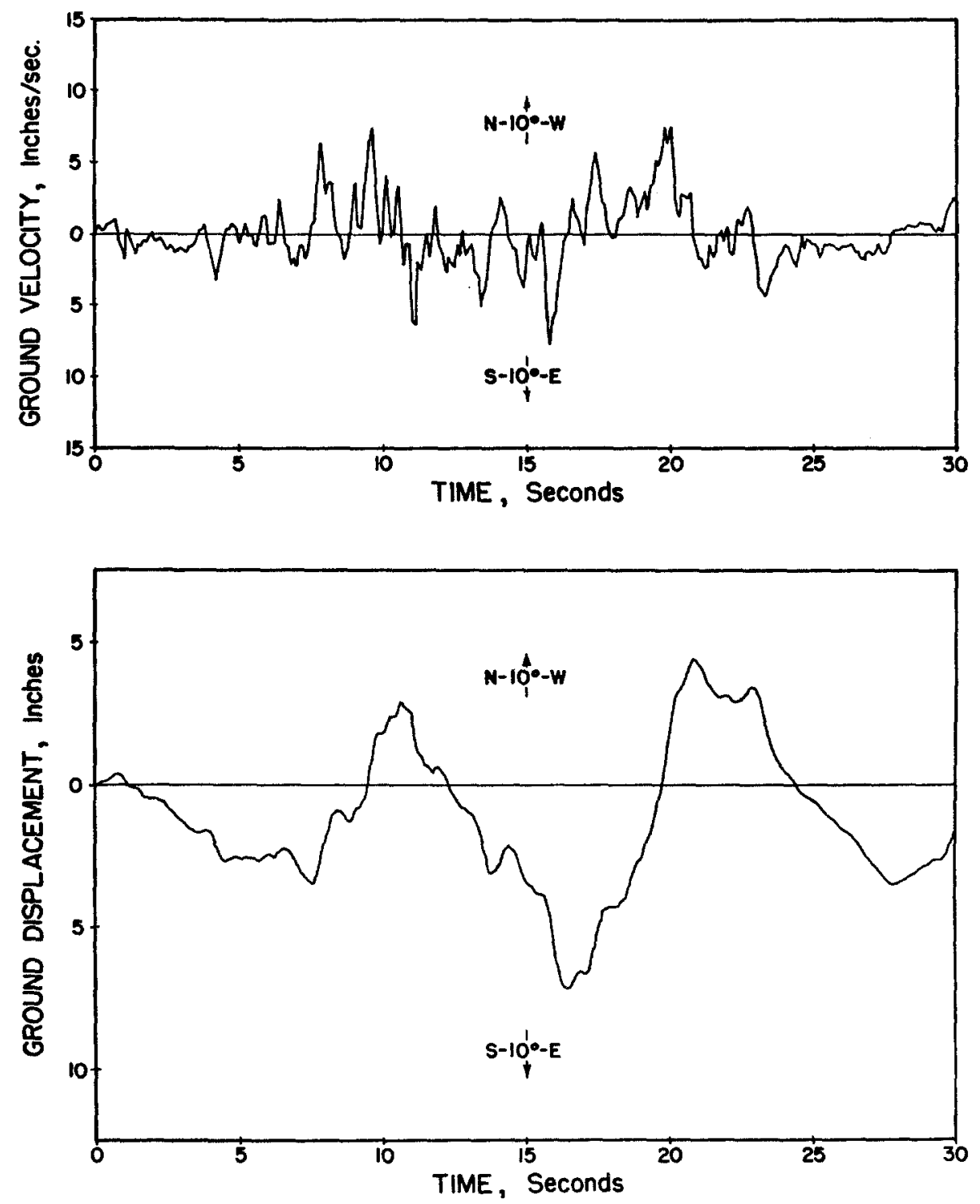

FIG. 8. Olympia, $1949, \mathrm{~N}-10^{\circ}-\mathrm{W}$ component. 
horizontal component indicates perhaps 5 inches of permanent displacement. The vertical component also indicates some upward displacement.
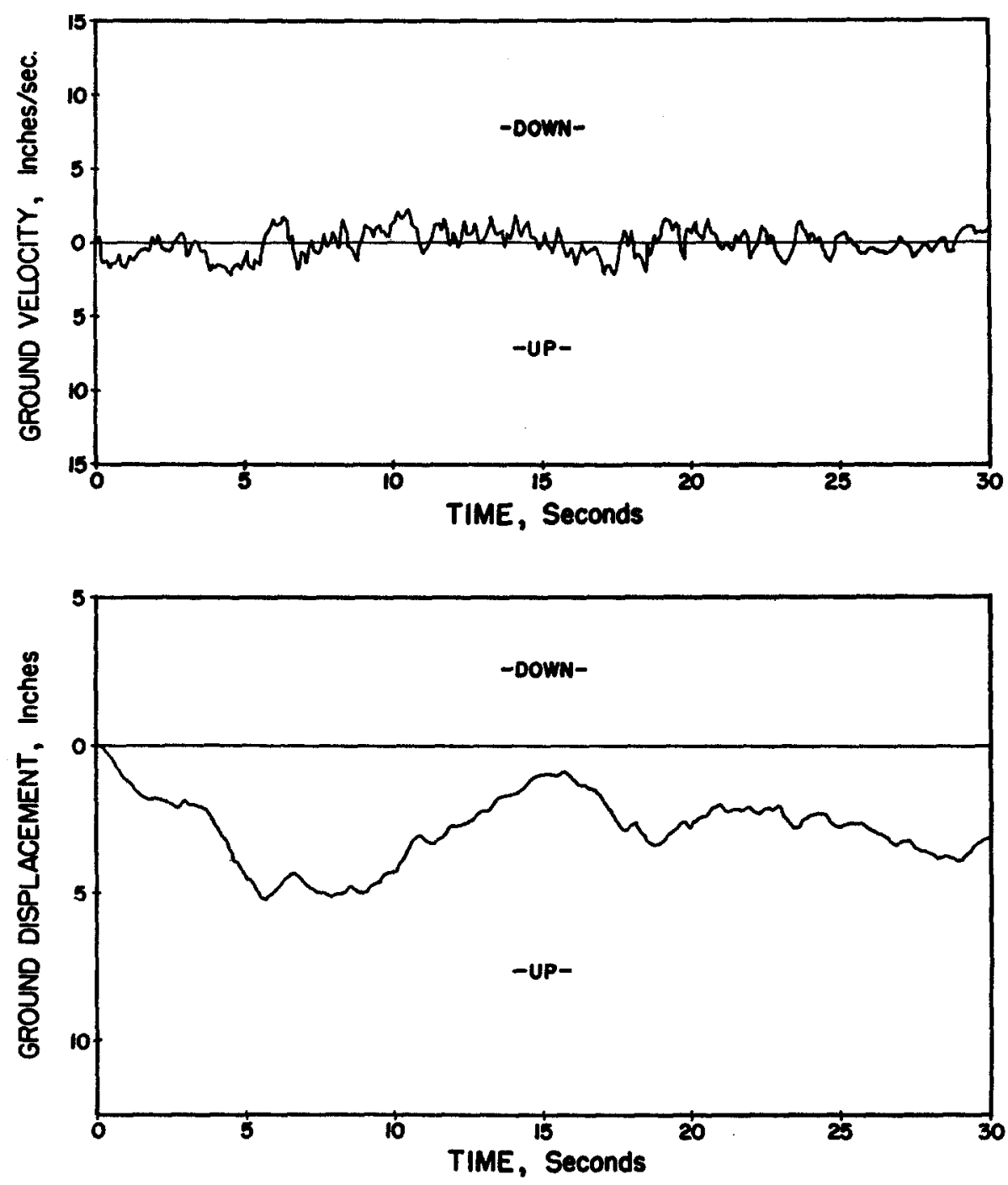

FrG. 9. Olympia, 1949, vertical component. 
Taft, 21 July 1952. This shock of Magnitude 7.7 centered approximately 40 miles east-southeast of the instrument. The White Wolf fault, on which the shock originated, is perpendicular to the San Andreas fault and the slipping was predominantly
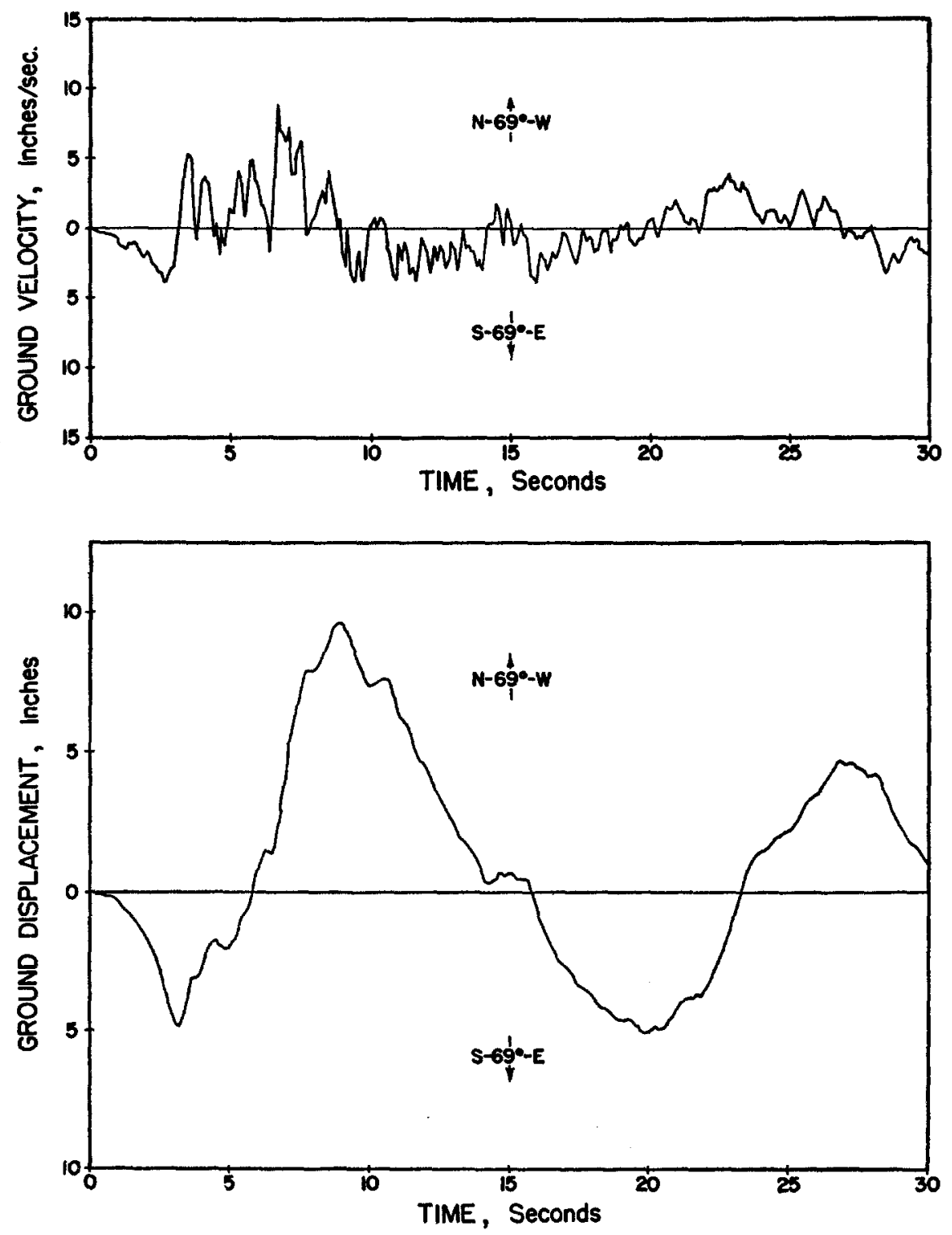

FIG. 10. Taft, $1952, \mathrm{~N}-69^{\circ}-\mathrm{W}$ component. 
vertical rather than the horizontal slipping usually associated with destructive California earthquakes. No permanent horizontal ground displacement is indicated but a small permanent downward displacement is indicated. The nature of the
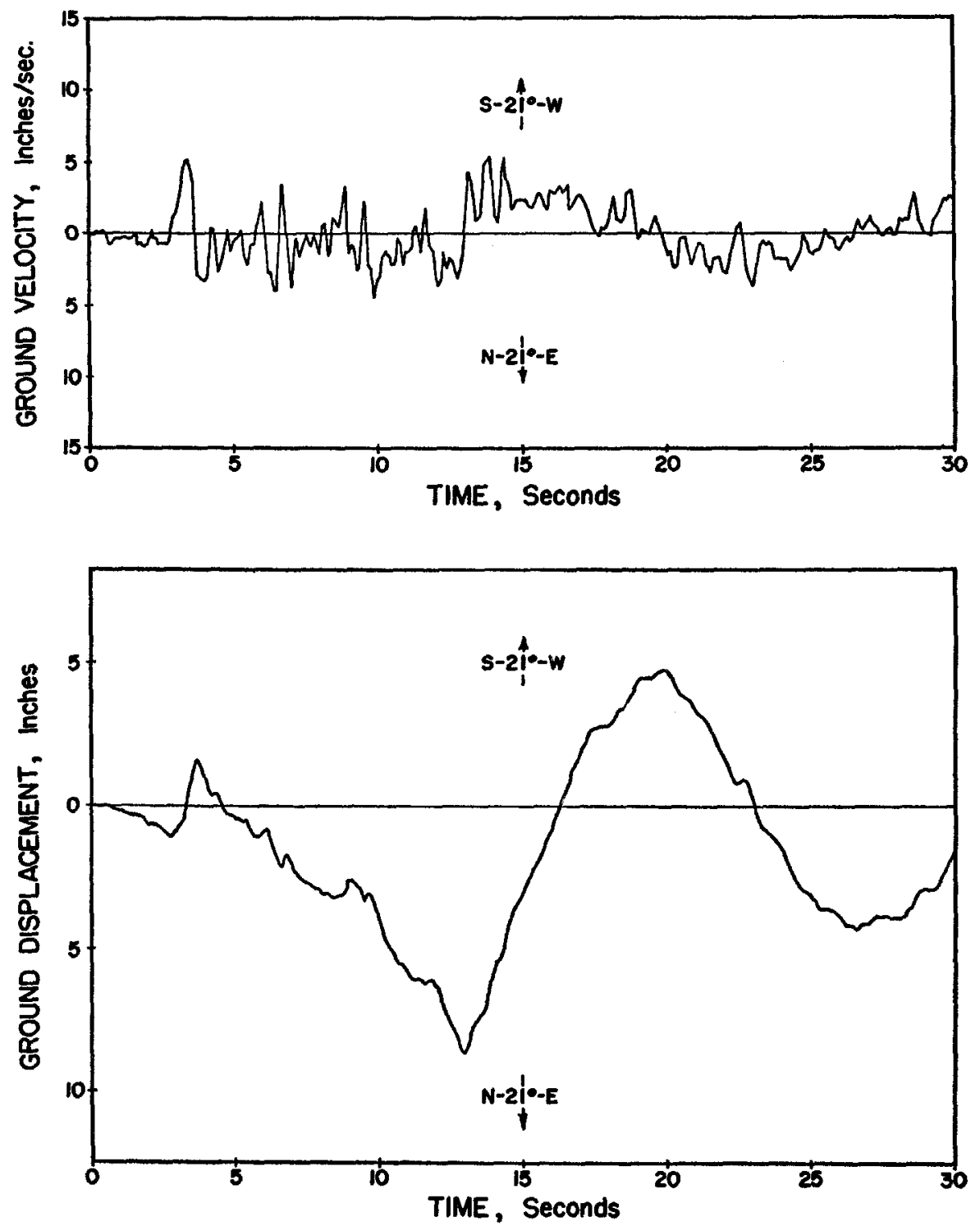

Frg. 11. Taft, 1952, N-21 ${ }^{\circ}$ E component. 
fault slip is reflected in the transient vertical ground displacement which is relatively larger than for the other three earthquakes. A permanent downward displacement would be consistent with the nature of the faulting.
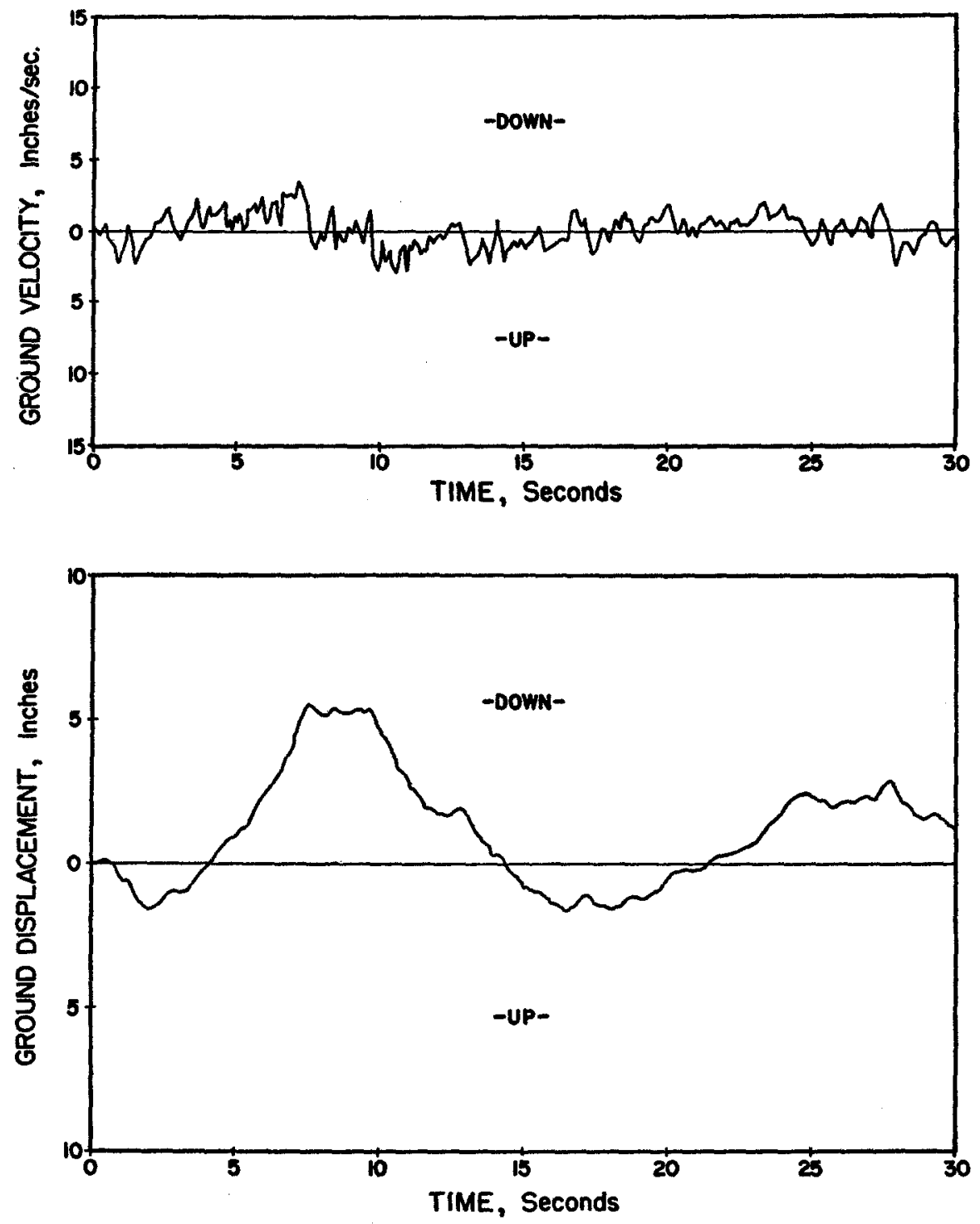

FIG. 12. Taft, 1952, vertical component. 


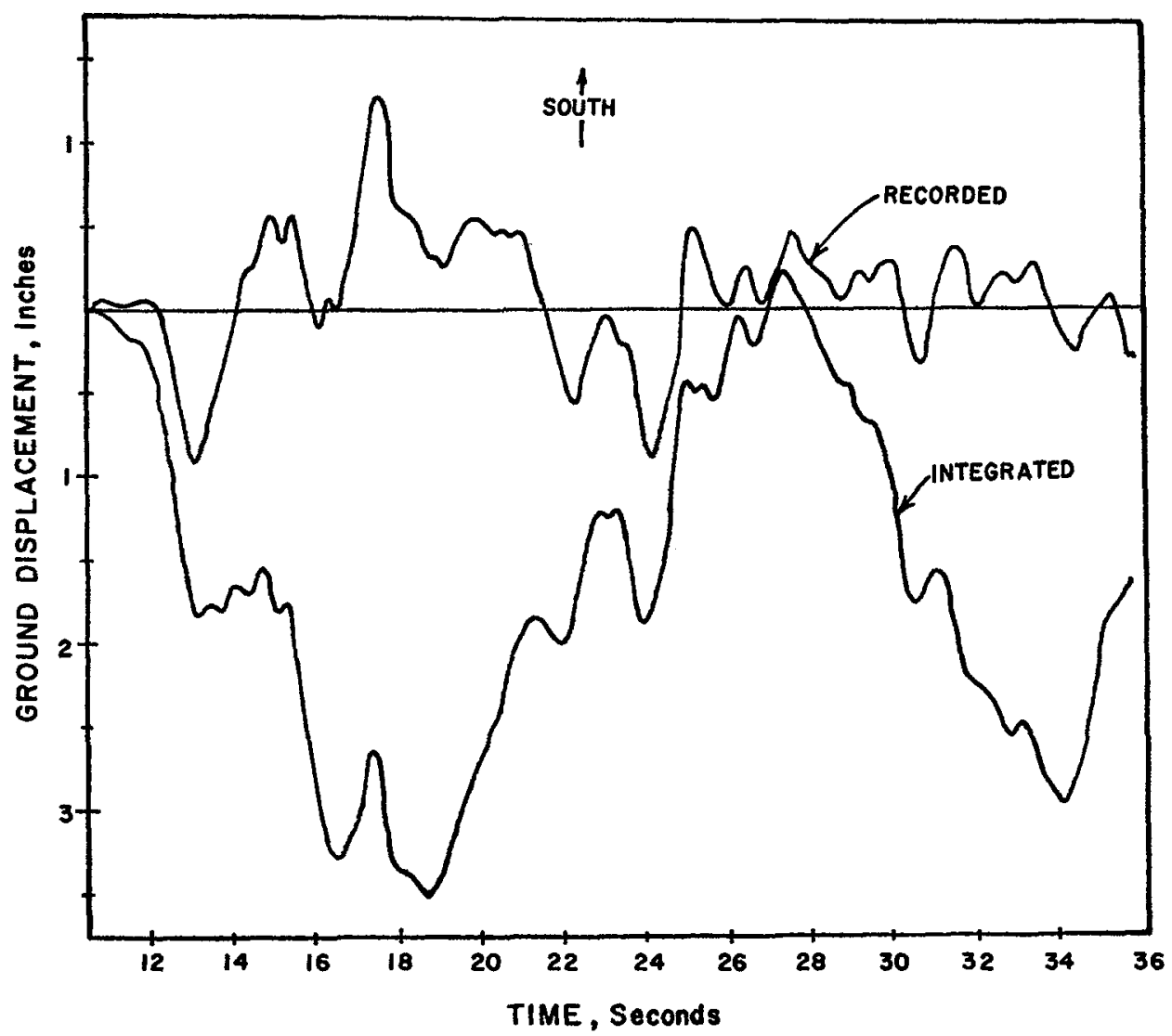

Fra. 13. Pasadena, 1952, N-S component.

Pasadena, 21 July 1952. The accelerometer on the campus of the California Institute of Technology was approximately 70 miles from the center of the shock and it recorded a maximum acceleration of 5 per cent of gravity. A 10-second period displacement meter also recorded the motion at the same location. Figure 13 shows a comparison between the north-south recorded and integrated displacements covering only the first twenty-four seconds of the ground motion. The 16-second period component that appears in the integrated displacement is too long to be recorded by the 10-second displacement meter. Aside from this, however, there is reasonable agreement between the recorded and integrated displacements.

G. V. B.

Department of Civil Engineering

UNIVERSITY OF Michigan

AnN ARbor, Michig. (N
G. W. H.

Division of Engineering,

California Institute of Technology, Pasadena, California. 